users. Drug use by young women is of particular concern and may lead to sexual health morbidity. We believe this group is currently under-recognised and opportunities for risk reduction are being missed.

\section{P096 CONCORDANCE OF CHLAMYDIA INFECTIONS OF THE RECTUM AND URETHRA IN SAME-SEX MALE PARTNERSHIPS: A CROSS-SECTIONAL ANALYSIS}

${ }^{1,2}$ Vincent Cornelisse* ${ }^{3}$ Christopher Sherman, ${ }^{1,4}$ Lei Zhang, ${ }^{1,2}$ Marcus Chen ${ }^{1,2}$ Catriona Bradshaw, ${ }^{1,2}$ Clare Bellhouse, ${ }^{1,2}$ Christopher Fairley, ${ }^{1,2}$ Eric Chow. ${ }^{1}$ Melbourne Sexual Health Centre, Melbourne, Australia; ${ }^{2}$ Monash University, Melbourne, Australia; ${ }^{3}$ University of Melbourne, Melbourne, Australia; ${ }^{4}$ The Kirby Institute, Sydney, Australia

10.1136/sextrans-2016-052718.150

\section{Background}

Sexual health services should ask all high risk attenders about drug and alcohol use. However, the impact of drug and alcohol use on STI epidemiology remains uncertain.

Aims To audit drug and alcohol history taking after introduction of a screening tool and to describe the patterns of use and associations with STI diagnoses.

Methods An anonymised database of all clients attending in 2015 was constructed including basic demographics, reported drug and alcohol history, HIV status and STI diagnoses.

Results 48,654 clients were seen in 2015. 26,429 (54\%) were asked about drug and/or alcohol use at least once. Use of any drug or excess alcohol was reported by $16 \%$ and was associated with higher rates of STIs (24 vs $10 \%, \mathrm{p}<0.001)$. Amongst MSM, 62\% had a drug and/or alcohol history taken, compared with $47 \%$ and $55 \%$ in heterosexual men (MSW) and women, respectively $(\mathrm{p}<0.0001)$. STIs diagnoses were significantly higher in drug users compared to non-users (27 vs 11\%), but were not different comparing alcohol excess vs no excess (14 vs 13\%). STI diagnoses were significantly higher in drug users compared to non-users in all sub-groups - MSM (41 vs 20\%) MSW ( 26 vs $18 \%$ ) women $(12$ vs $7 \%$ ) - all p $<0.0001$.

Conclusions The audit showed room for improvement in history taking. Chemsex drugs are associated with the highest risk of STIs. This relationship might not be causal. Party drug use was associated with some STIs. The audit supports drug and alcohol histories for all MSM as well as heterosexual men and women attending with STIs.

\section{P097 ARE PATIENTS IN RURAL COMMUNITIES INTERESTED IN ONLINE SEXUAL HEALTH SERVICES?}

${ }^{1}$ Amy Pearce ${ }^{*}$, ${ }^{2}$ Rachael Penrose, ${ }^{1}$ Joanne Palmer, ${ }^{1}$ Thomas Perrin, ${ }^{1}$ Frances Keane. ${ }^{1}$ Royal Cornwall Hospital, Truro, UK; ${ }^{2}$ Plymouth College of Medicine and Dentistry, Plymouth, UK

\subsection{6/sextrans-2016-052718.151}

Background/introduction People do not attend Genitourinary Medicine (GUM) services for reasons including cultural beliefs and stigma. In Cornwall geographical isolation, poor transport and local Council budgetary cuts to peripheral clinics also limit access.

$\operatorname{Aim}(\mathrm{s}) /$ objectives To ascertain whether patients would use online services to book appointments and/or order home testing kits.

Methods An anonymised questionnaire survey of GUM patients. Data was recorded into an Excel spreadsheet and analysed using SPSS.

Results 248 questionnaires were returned from women(59.7\%) and men(40.3\%) aged $13-72$ years. 154 (62.3\%) were previous

Abstract P096 Table 1 Association of reported drug and alcohol use and STI diagnosis in 2015

\begin{tabular}{|c|c|c|c|c|c|c|c|}
\hline & & $\begin{array}{l}{ }^{1} \text { Chems Yes, \% } \\
N=26,429 \text { asked }\end{array}$ & ${ }^{4} p$-value & $\begin{array}{l}{ }^{2} \text { Party Yes, } \% \\
N=26,429 \text { asked }\end{array}$ & ${ }^{4} p$-value & $\begin{array}{l}{ }^{3} \text { Alcohol excess, } \% \\
N=20,406 \text { asked }\end{array}$ & ${ }^{4} p$-value \\
\hline \multirow[t]{2}{*}{ Total } & & $4.4 \%$ & & $12 \%$ & & $6 \% n=1225$ & \\
\hline & & $\mathrm{n}=1046$ & & $\mathrm{n}=2891$ & & & \\
\hline Gender/ & MSM & 16.5 & $<0.0001$ & 15.9 & $<0.0001$ & 8.7 & $<0.0001$ \\
\hline \multirow[t]{2}{*}{ Sexual orientation (MSW-heterosexual men) } & MSW & 0.9 & & 18.2 & & 9.1 & \\
\hline & Women & 0.3 & & 7.1 & & 3.9 & \\
\hline \multirow[t]{2}{*}{ New STI this year } & Yes & 17.0 & $<0.0001$ & 19.6 & $<0.0001$ & 6.6 & 0.156 \\
\hline & No & 2.4 & & 10.9 & & 5.9 & \\
\hline \multirow[t]{2}{*}{ Chlamydia } & Yes & 14.0 & $<0.0001$ & 19.1 & 0.435 & 7.1 & 0.257 \\
\hline & No & 20.6 & & 20.2 & & 6.0 & \\
\hline \multirow[t]{2}{*}{ Gonorrhoea } & Yes & 33.2 & $<0.0001$ & 23.8 & $<0.0001$ & 6.8 & 0.753 \\
\hline & No & 7.8 & & 17.2 & & 6.5 & \\
\hline \multirow[t]{2}{*}{ Syphilis } & Yes & 40.1 & $<0.0001$ & 21.7 & 0.320 & 4.7 & 0.191 \\
\hline & No & 14.5 & & 19.3 & & 6.8 & \\
\hline \multirow[t]{2}{*}{ HSV } & Yes & 8.0 & $<0.0001$ & 17.4 & 0.190 & 5.3 & 0.205 \\
\hline & No & 18.6 & & 20.0 & & 6.9 & \\
\hline \multirow[t]{2}{*}{ Hepatitis B } & Yes & 17.1 & $<0.006$ & 9.7 & 0.252 & 6.7 & 1.000 \\
\hline & No & 0 & & 19.7 & & 6.6 & \\
\hline \multirow[t]{2}{*}{ Hepatitis C } & Yes & 65.7 & $<0.0001$ & 45.7 & $<0.0001$ & 0 & 0.166 \\
\hline & No & 16.4 & & 19.3 & & 6.7 & \\
\hline
\end{tabular}

${ }^{1}$ "Chemsex drugs" (mephedrone, gamma-Hydroxybutyric acid, methamphetamine)

2"Party drugs" (cannabis, ecstasy/MDMA, cocaine, ketamine)

${ }^{3}$ Excess alcohol use was $>14$ units for women and $>21$ units for men.

${ }^{4} \mathrm{p}$-values calculated using Chi squared or Fisher exact test as appropriate. 